\title{
Erratum to: Rendezvous-based data dissemination for supporting mobile sinks in multi-hop clustered wireless sensor networks
}

\author{
Euisin Lee ${ }^{1} \cdot$ Soochang Park $^{2} \cdot$ Seungmin $\mathrm{Oh}^{3} \cdot$ Sang-Ha Kim ${ }^{3}$
}

Published online: 9 July 2015

(C) Springer Science+Business Media New York 2015

\section{Erratum to: Wireless Netw (2014) 20:2319-2336 DOI 10.1007/s11276-014-0735-9}

Unfortunately, the coauthor's (Dr. Euisin Lee) affiliation has been published incorrectly in the original publication of the article. The correct version should read as given below:
"School of Information and Communication Engineering, Chungbuk National University, Cheongju, Korea".

The online version of the original article can be found under doi:10. 1007/s11276-014-0735-9.

Sang-Ha Kim

shkim@cnu.ac.kr

Euisin Lee

eslee@chungbuk.ac.kr

Soochang Park

Soochang.PARK@telecom-sudparis.eu

Seungmin Oh

smoh@cclab.cnu.ac.kr

1 School of Information and Communication Engineering, Chungbuk National University, Cheongju, Korea

2 Réseaux et Services Multimedia Mobiles (RS2M) Département, Telecom SudParis, Evry, France

3 Computer Engineering Department, Chungnam National University, Taejon, Korea 